\title{
Analysis of laser therapy effects in Sporothrix schenckii inactivation in vivo
}

\author{
Gunther Monteiro de Paula Guirado ${ }^{1,2}$, Luciano dos Santos Feitosa ${ }^{3}$, Dora Inés Kozusny-Andreani ${ }^{4,5}$, \\ Ricardo Scarparo Navarro ${ }^{1,6,7 *}$ \\ ${ }^{1}$ Biomedical Engineering Program, Brasil University, São Paulo, SP, Brazil. \\ ${ }^{2}$ Faculty of Medicine, Taubaté University, Taubaté, SP, Brazil. \\ ${ }^{3}$ Department of Microbiology and Immunology, Federal University of São Paulo, São Paulo, SP, Brazil. \\ ${ }^{4}$ Ambiental Sciences Program, Brasil University, Fernandópolis, SP, Brazil. \\ ${ }^{5}$ Faculty of Medicine, Brasil University, Fernandópolis, SP, Brazil. \\ ${ }^{6}$ Bioengineering Program, Brasil University, São Paulo, SP, Brazil. \\ ${ }^{7}$ Faculty of Dentistry, Brasil University, São Paulo, SP, Brazil.
}

\begin{abstract}
Introduction: Sporotrichosis is a common disease in tropical regions, caused by the fungus Sporothrix schenckii, affecting mainly rural workers and in direct contact with animals. Although treatment by indiscriminate use of oral antifungal drugs gives rise resistant isolates, leading to therapeutic failures and no remission of the disease. To evaluate the effectiveness of red low-power laser photobiomodulation in inactivation of $S$. schenckii infection induced in rodents. Methods: Subcutaneously inoculation $\left(2 \times 10^{3}\right.$ S. schenckii $/ \mathrm{ml}, 0.2 \mathrm{ml}$ suspension) in the left footpad, in 27 mice divided into: control $(n=6$, inoculated, without irradiation): early stage (not inoculated $)=1^{\text {th }}$ biopsy; intermediate ( 9 weeks of evolution $)=2^{\text {nd }}$ biopsy; final $(21$ weeks of evolution $)=3^{\text {th }}$ biopsy. Treated $(n=21$, inoculated and irradiated $)$ : early (13 weeks of evolution, 4 weeks after first irradiation $)=4^{\text {th }}$ biopsy, intermediate $(17$ weeks of evolution, 8 weeks after first irradiation $)=5^{\text {th }}$ biopsy, final $(21$ weeks of evolution, 12 weeks after first irradiation $)=6^{\text {th }}$ biopsy. Serial irradiation with biopsies occurred every 30 days during each month, for three months. At the end of testing, the mice were euthanized, and histological analyzes of biopsies were performed. Results: Each laser treatment session showed an inactivation of $S$. schenckii in treated animals compared to controls, with a regression of pseudoepitheliomatous hyperplasia, chronic inflammation, neutrophils, granulomas, giant mononuclear cells and steroid corpuscles. Conclusion: The laser photobiomodulation was effective on S. schenckii inactivation, appearing to be an interesting therapeutic option in infections caused by this organism.
\end{abstract}

Keywords Laser therapy, Low-power laser, Sporothrix schenckii, Sporotrichosis, Photobiomodulation.

\section{Introduction}

Sporotrichosis is a disease that has as its etiological agent the dimorphic fungus Sporothrix schenckii. Although widely distributed in nature, occupying basically all regions of the globe (Barros et al., 2011; Lopes-Bezerra et al., 2006), its predominance occurs in places of tropical and subtropical climate (Barros et al., 2011). Infection with $S$. schenckii occurs mainly due to body regions containing microtraumas, which facilitate the entry of the fungus into the organism, entering into contact with

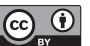

This is an Open Access article distributed under the terms of the Creative Commons Attribution License, which permits unrestricted use, distribution, and reproduction in any medium, provided the original work is properly cited.

How to cite this article: Guirado GMP, Feitosa LS, Kozusny-Andreani DI, Navarro RS. Analysis of laser therapy effects in sporothrix schenckii inactivation in vivo. Res Biomed Eng. 2018; 34(2):93-101. DOI: $10.1590 / 2446-4740.06917$

*Corresponding author: Biomedical Engineering and Bioengineering Programs, Brasil University, Rua Carolina Fonseca, 245, Itaquera, CEP08230-030, São Paulo, SP, Brazil. E-mail: ricardosnavarro@gmail.com Received: 03 Nov 2017 / Accepted: 28 Mar 2018 contaminated soil, vegetables and organic matter, such as thorns, dry leaves and wood (Barros et al., 2011; Lopes-Bezerra et al., 2006). Thus, certain occupational activities, such as floriculture, agriculture, mining and logging, or even recreational activities, are traditionally associated with S. schenckii infections (Barros et al., 2011).

Regarding the laboratory findings, the colonies of $S$. schenckii present a membranous appearance, demonstrating a certain wrinkling of their surface. In culture, they initially presented whitish coloration, gradually evolving to tones of brown, dark gray and, finally, black coloration. In some subcultures, it is possible to verify the occurrence of a loss of dark tonality, which causes them to have a yellowish-white coloration (Lopes-Bezerra et al., 2006).

In the last decade, the frequency of fungal infections has increased considerably, resulting in a significant increase in the morbidity and mortality rates associated with these clinical conditions. Sporotrichosis, which has long been classified as a neglected disease, is now considered an emerging disease in several countries, 
such as Peru, Mexico, India, and Brazil, among others (Carlos and Batista-Duharte, 2015).

In a recent study conducted in Peru by Oyarce et al. (2016), 94 patients with a positive diagnosis for sporotrichosis were evaluated, the majority of them were males and residents of poor regions distributed throughout the country. The cutaneous and lymphocutaneous forms of the disease were the most commonly observed, especially affecting the upper limbs. Of the patients evaluated, about $15 \%$ developed various comorbidities associated with $S$. schenckii infection.

Da Rosa et al. (2005) performed a study in Brazil with 304 sporotrichosis carriers, confirmed by fungus culture or histopathological examination. The authors did not identify statistically significant differences between the prevalence of the cutaneous and lymphocutaneous forms of the disease. Similarly to Oyarce's study (2016), the upper limbs were the region of the body most affected by the infection, although several cases involving the pubic region were also identified (Rosa et al., 2005).

More than ten years after the publication of the results of Rosa et al. (2005), in a recent study evaluating 25 patients with $S$. schenckii infection in the state of São Paulo conducted by Marques et al. (2015), despite the small size of the sample, a high prevalence of the disease was also found in male individuals, mostly rural workers, who also had their upper limbs as the region most affected by the microorganism. This study differed from others (Oyarce et al., 2016; Rosa et al., 2005) because it emphasized sporotrichosis in its lymphocutaneous form as the most prevalent in the majority of individuals followed up.

Although it occurs more frequently in poor countries, sporotrichosis can also occur in nations with economic realities quite different from those commonly found in countries endemic for the disease. For example, in a study conducted in Japan by Takenaka et al. (2014), which evaluated the 165 cases that occurred between 1951 and 2012 in that country, a higher prevalence of the cutaneous form was observed, also in men involved in activities related to land, and with greater involvement of the upper limbs, followed by the face. Cases of the disease have also been reported in countries such as France, Italy, and the United States (Barros et al., 2011).

The clinical presentation of sporotrichosis may vary according to host immune status, proportion, and depth of infection. The cutaneous form of the disease usually occurs in patients who have had previous contact with $S$. schenckii and were reinfested, whereas the lymphocutaneous form is the most common form of contact with the microorganism (Barros et al., 2011). Lesions resulting from sporotrichosis exert pressure on tissues located below the skin, causing ulceration and releasing purulent secretions. With the evolution of the disease, infection can reach regional lymph nodes, or even cause a systemic attack (Barros et al., 2011; Lopes-Bezerra et al., 2006). In more severe cases, ocular, nasal, pulmonary, osteoarticular and meningeal lesions may occur, as well as generalized infection (Lopes-Bezerra et al., 2006).

The treatment of sporotrichosis can be performed based on diverse procedures. In general, after confirmation of the diagnosis, pharmacological treatment is instituted. Potassium iodide is a medicine widely used to combat especially the lymphocutaneous form of the disease, acting as an antifungal and immune system stimulant. Several essentially antifungal drugs, such as itraconazole, fluconazole and ketoconazole are indicated to combat both forms of sporotrichosis. Terbinafine, which has a fungistatic, fungicidal and antimycotic function, has been the standard choice for combating the cutaneous form of $S$. schenckii infections. Amphotericin is recommended for cases that are more complex, with a systemic attack (Bonifaz et al., 2015; Mahajan, 2014).

It is well known that the worldwide epidemic of resistance to drug treatments combatting infections, including those targeted at fungal infections, has greatly impaired the success of such therapies. The unrestricted use of some antifungals stimulates the natural selection of resistant strains, progressively reducing the action of the drug and, in some cases, considerably increasing the mortality rate of the patients affected (Gould, 2009). In this sense, there is an increasing need to seek alternative therapies for the use of antifungals.

Some alternative forms of sporotrichosis treatment may contribute to reducing the use of antifungal agents. Among them, thermotherapy, which is recommended for cutaneous and lymphocutaneous forms of the disease, especially in pregnant women where antifungal therapy should not be instituted, and cryotherapy, which can be used as a single treatment or in combination with certain medications, may be cited (Bonifaz et al., 2015).

Several studies have reported the possibility of using a low-power laser in many areas of medicine, such as in vitro experiments to reduce the rate of apoptosis (Silva et al., 2016), experimental models to reduce tetanic contractions (Giaretta et al., 2016), improvement in muscle function (Giaretta et al., 2015), treatment of acute medullary trauma (Abreu et al., 2011) pulmonary inflammation (Oliveira et al., 2010), bone defects (Feitosa et al., 2012), tendinopathies (Bjordal et al., 2003), neuro-rehabilitation (Hashmi et al., 2010), chronic obstructive pulmonary disease (Alves et al., 2010), and as an alternative treatment therapy of various diseases caused by microorganisms (Dai et al., 2009; Donnelly et al., 2008; Gilaberte et al., 2014; Hees et al., 2012; Javed et al., 2014; Kozarev, 2010; Soukos and Goodson, 2011). 
In a systematic review conducted by Donnelly et al. (2008) identified that organisms from the dermatomycetes class, in addition to yeasts, can be completely eliminated from cultures with the use of photodynamic therapy. In a clinical study conducted by Kozarev (2010) in the dermatology sector of a private institution, 72 patients with 194 different onychomycoses were treated with $\mathrm{Nd}$ :YAG laser in four sessions, with intervals of one week between each session. For the main results, the author pointed out that more than $95 \%$ of the patients presented complete remission of the infectious disease, and that the treatment had no side effects. However, the effects reported in the Kozarev's study were not confirmed by Hees et al. (2012), who in an in vitro experiment did not observe antimicrobial effects from photodynamic therapy in cultures of microorganisms associated with onychomycosis.

Javed et al. (2014), in a systematic review which sought to evaluate studies using a low-power laser in the treatment of orally acquired fungal infections, reported the efficacy of therapy in the fifteen selected studies, even though they used varying wavelengths, and different types of photosensitizers and exposure times.

Also in a literature review conducted by Baltazar et al. (2015), the authors concluded that photodynamic therapy has a very promising future in the fight against certain pathogenic fungi, particularly the dermatophytes. One of the studies cited by the authors is that of Gilaberte et al. (2014), who, after experiments conducted in vitro, identified a potent fungicidal effect of low-power a laser on etiological agents of subcutaneous mycosis, especially Sporothrix schenckii.

The interest in efficient and alternative fungicide treatments for drug use is increasing, especially due to the increase of fungal pathogens responsible for nosocomial infections and opportunistic mycoses in immunocompromised patients. Safe and specific agents are scarce, many have high toxicity, and most of them have only fungistatic action. In addition, the routine use of antifungal therapy leads to the progressive emergence of treatment-resistant strains of microorganisms. Thus, the potential, beneficial effect of low power laser phototherapy in several areas of medicine, especially for the remission of fungal infections, is considered to be a promising alternative for the treatment of sporotrichosis. Recently, Guirado et al., (2017) had been showed that Sporothrix schenckii can be inactivated by use of photodynamic therapy.

This study evaluated the effects of low power red laser photobiomodulation (PBM) targeting biomodulation of cellular function of fibroblasts and by inhibiting the enzymes that destroy the cutaneous collagen metalloproteinases, release of pro-inflammatory mediators, chemotaxis of inflammatory cells and defense, with the modulation of local inflammation, activation of the systemic and local immune activity, which may correct and/or balance the metabolic functions that have changed in skin and mucous membrane cells infected by the fungus. Promoting reduction of microbial activity as side effect of local tissue irradiated PBM. Leading to question the possible effects of PBM laser for the treatment of Sporotrichosis, this being of lowest cost, shortest time and side effects compared to the antifungal drugs.

\section{Methods}

Male Swiss strain mice from the Production and Experimentation Laboratory of the Faculty of Pharmaceutical Sciences and Institute of Chemistry of the University of São Paulo (USP), weighing on average 25 grams, and aged between 40 and 50 days, were used in the present study. The animals were housed in collective cages containing 3 animals each, containing feed and water ad libitum. All the procedures used in this research were authorized by the Animal Ethics Committee ( $\left.\mathrm{n}^{\circ} 1002 / 15\right)$.

The strain used in Sporothrix schenckii (Ss40) came from the Federal University of São Paulo (UNIFESP) laboratory, a mycology collection which is available in the Specialized Medical Mycology Center. Preparation and subsequent subcutaneous inoculation of yeast cells in $2 \times 10^{3} \mathrm{~S}$. schenckii / $\mathrm{ml}$ into the left plantar surface $(0.2 \mathrm{ml}$ of inoculum suspension) (28.29) in 27 mice were performed. These were divided into the control group ( $\mathrm{n}=6$, not submitted to treatments), and treated $(\mathrm{n}=21$, irradiated with a low-power red laser). During the tests, the animals were maintained at room temperature $\left(15^{\circ} \mathrm{C}\right.$ to $\left.30^{\circ} \mathrm{C}\right)$, relative humidity (from $30 \%$ to $75 \%$, non-condensing), and atmospheric pressure (between $700 \mathrm{hPa}$ to $1060 \mathrm{hPa}$ ).

The irradiations were performed sequentially one time every 30 days for three months (total three irradiations sessions). The present study used a low power red light emitting optical diode source, with a wavelength of $660 \mathrm{~nm}$ Gallium Aluminum Arsenide (Recover, MMOptics ${ }^{\circledR}$, São Carlos, Brazil), with power of $100 \mathrm{~mW}$. Regarding the beam diameter, the punctual technique (the strategic point chosen over the injured area for the laser application), in contact mode was used, considering the useful area of the tip was $3 \mathrm{~mm}^{2}$. The laser continuous emission mode were applied with constant shape, duration and amplitude. The energy for laser photobiomodulation of soft tissue repair were $0.6 \mathrm{~J}$ per application point, 6 seconds of irradiation per point, totaling $1.2 \mathrm{~J}$ and energy density of $24 \mathrm{~J} / \mathrm{cm}^{2}$ in the treated area (about $5 \mathrm{~mm}^{2}$ ). The experimental protocol used in the present experiment followed the models proposed in 2009 by Antunes et al. (2009) and Campos (2013). 
At the end of the tests, all mice were submitted to euthanasia with a lethal dose of intraperitoneal sodium Thiopental (100 mg/kg body weight), as proposed by Abreu et al. (2011), after which biopsies were collected from the inoculation region based on the $4 \mathrm{~mm}$ diameter punch technique, to perform histopathological analyzes. The removed material was fixed in $10 \%$ formaldehyde for staining with the hematoxylin-eosin method. Histological sections were evaluated under optical microscope in a clinical laboratory by a pathologist. All samples from the 27 inoculated animals, both controls $(n=6)$ and irradiated $(n=21)$, were evaluated for several alterations, such as pseudoepitheliomatous hyperplasia (if present or absent); chronic inflammatory process, based on the presence of mononuclear cells (if present or absent, and if present, in which intensity: low, moderate or high); acute inflammatory activity, based on the presence of neutrophils (taking into account the same criteria for evaluation of chronic inflammation); granulomas, mononuclear giant cells and steroid corpuscles (whether present or absent). Also, an evaluation by the Periodic Acid Schiff Technique (negative or positive, and when positive, the number of spores was calculated).

\section{Results}

In the design of this present study the first biopsy was performed to make sure that the control mice, were not infected and to have a result about a standard histopathological normal tissue. After this biopsy these animals were inoculated and accompanied by 21 weeks. Second biopsy was carried out of the control mice, 21 weeks after infected, to make sure about the evolution as well, to have a result about a standard tissue histopathology infected and untreated with laser therapy

The results of present study demonstrated that: Control Group ( $\mathrm{n}=6$, inoculated, without irradiation): in the early stage (not inoculated) (1 th biopsy): Histopathology: Demonstrated without pseudoepiteliomatous hyperplasia, absence of chronic and acute inflammatory process. No detectable presence of granulomas, giant cells and mononuclear corpuscles steroids. In the Technique of Schiffer's periodic acid results in negative for the presence of spores.

Control Group ( $\mathrm{n}=6$, inoculated, without irradiation): in the intermediate stage ( 9 weeks of evolution $)\left(2^{\text {nd }}\right.$ biopsy): Histopathology: Demonstrated subacute and chronic inflammatory process, granulomas from fungal activity, with pseudoepiteliomatous hyperplasia. Detectable presence of giant cells and mononuclear corpuscles steroids. In the Technique of Schiffer's periodic acid results in positive for the presence of spores $(n=20)$.

Control Group ( $\mathrm{n}=6$, inoculated, without irradiation): in the final stage ( 21 weeks of evolution) ( $3^{\text {th }}$ biopsy):
Histopathology: Demonstrated intense subacute and chronic inflammatory process, granulomas from fungal activity, in the Technique of Schiffer's periodic acid results in positive for the uncountable presence of spores.

In the Treated Group $(n=21$, inoculated and irradiated): in the early stage (13 weeks of evolution, 4 weeks after first irradiation) ( $4^{\text {th }}$ biopsy): Histopathology: Demonstrated moderate degree of fibrosis in the reticular dermis, low chronic inflammatory process, remission of acute inflammatory process, granulomas from fungal activity, in the Technique of Schiffer's periodic acid results in negative (absence of spores); In the intermediate stage (17 weeks of evolution, 8 weeks after first irradiation) ( $5^{\text {th }}$ biopsy): Histopathology: Demonstrated without pseudoepiteliomatous hyperplasia and chronic and acute inflammatory process. Absence of granulomas, giant cells and mononuclear corpuscles steroids, in the Technique of Schiffer's periodic acid results in negative (absence of spores). In the Final stage (21 weeks of evolution, 12 weeks after first irradiation) ( $6^{\text {th }}$ biopsy): Histopathology: Demonstrated without pseudoepiteliomatous hyperplasia and chronic and acute inflammatory process. Absence of granulomas, giant cells and mononuclear corpuscles steroids, in the Technique of Schiffer's periodic acid results in negative (absence of spores).

Figure 1 represents the histological section obtained from the biopsy of a control animal, without inoculation and without irradiation. In the image, abnormalities such as pseudoepitheliomatous hyperplasia, chronic and acute inflammatory processes, granulomas, mononuclear giant cells and steroid corpuscles, common in sporotrichosis, are not present, thus classifying the sample as within normality. Furthermore, the Periodic Acid Schiff technique was negative for the presence of spores. This sample was then used as the basis of comparison for the other histological sections.

Figure 2 shows a histological section obtained from biopsy performed 9 weeks after inoculation with S. schenckii, and prior to low-power laser therapy. In this section, the epidermis, the papillary, superficial reticular and the intermediate dermis (partially) were visualized. In the image, it is possible to identify subacute and chronic inflammatory process, besides the presence of granulomas originating in the local fungal activity. Pseudoepitheliomatous hyperplasia, mononuclear giant cells and steroid corpuscles were not observed in said specimen. The Periodic Acid Schiff Technique identified the presence of 20 spores.

In Figure 3, where it is possible to observe the histological cut resulting from a biopsy performed 13 weeks after the $S$. schenckii inoculation, and 4 weeks after the first laser therapy session, a moderate degree of fibrosis of the reticular dermis is identified, concomitantly with 


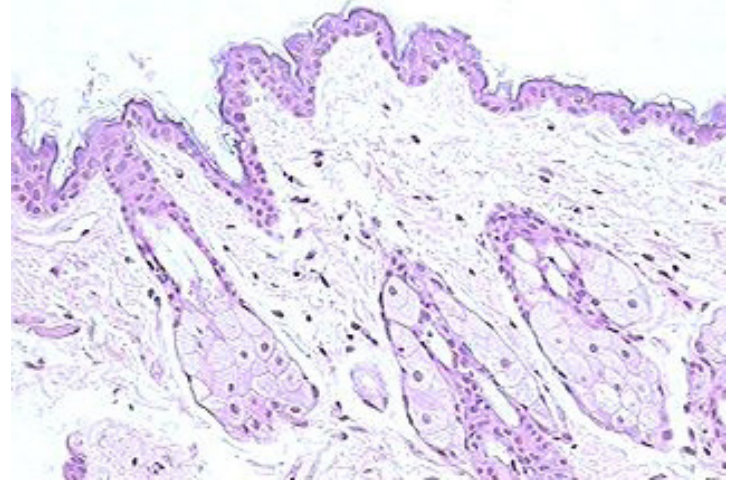

Figure 1. Histological preparation of a control animal biopsy, absence of inoculation (100x magnification).

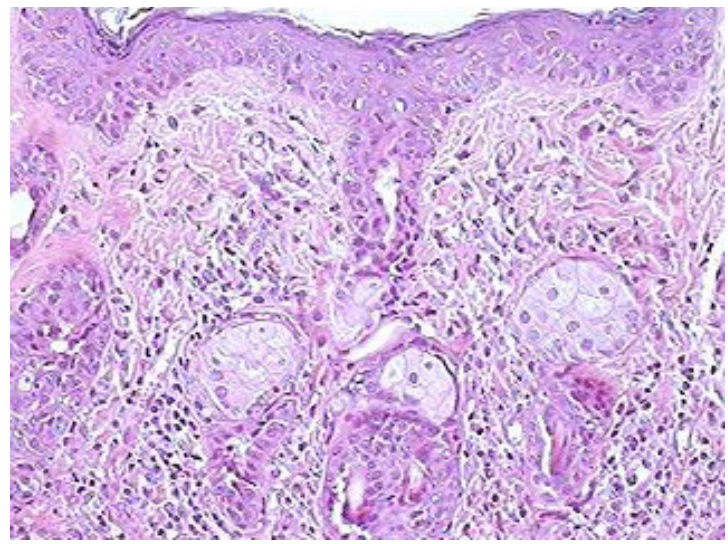

Figure 2. Histological preparation of an animal biopsy of the irradiated group, 9 weeks after inoculation of $S$. schenckii-containing preparation, and prior to low-power laser therapy (100x magnification).

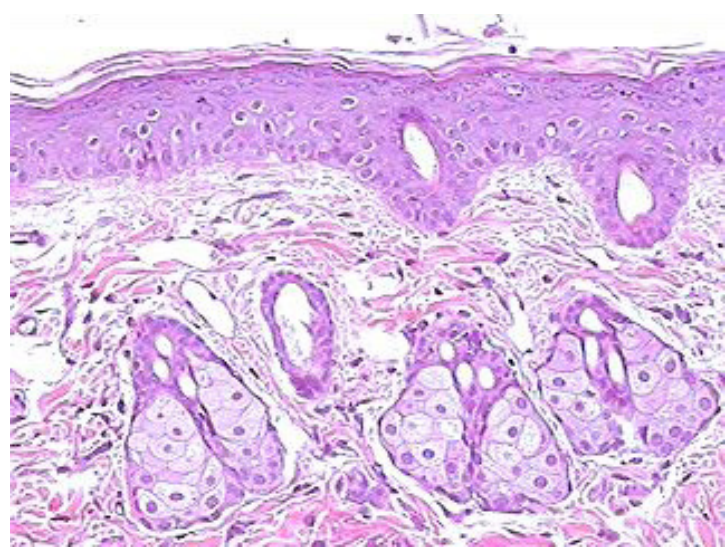

Figure 3. Histological preparation of an animal biopsy of the irradiated group, 13 weeks after inoculation of $S$. schenckii-containing preparation, and 4 weeks after the first session of low-power laser therapy (100x magnification) a mild chronic inflammatory process, with remission of the acute inflammatory process and granulomas. No other histological changes were identified. The results for the Periodic Acid Schiff technique were negative.

Figure 4 shows the histological section containing a superficial sample represented by epidermis, papillary dermis and superficial reticular dermis, from a second biopsy performed after the second irradiation session ( 8 weeks after the first session and 17 weeks after inoculation). In the specimen, no histological changes could be observed. Further, the results for the Periodic Acid Schiff technique was remained negative.

In Figure 5, represented by a histological cut from a biopsy containing a sample of epidermis, papillary dermis and superficial reticular dermis, as well as was

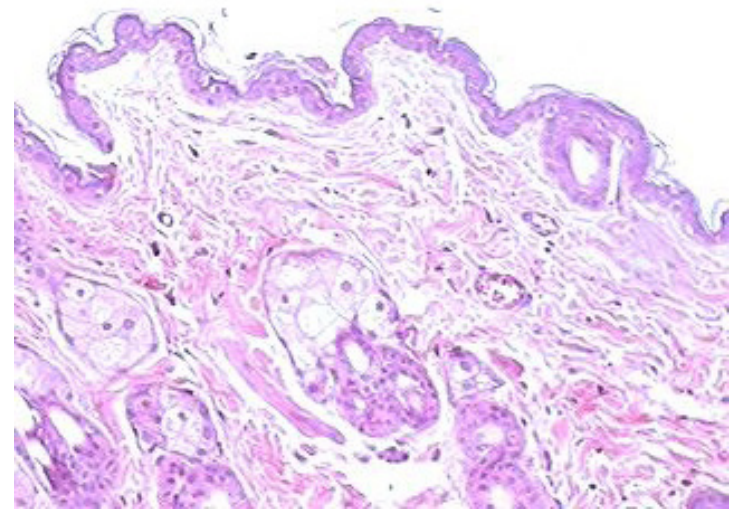

Figure 4. Histological preparation of an animal biopsy of the irradiated group, performed after the second irradiation session ( 8 weeks after the first session, and 17 weeks after $S$. schenckii inoculation) (100x magnification).

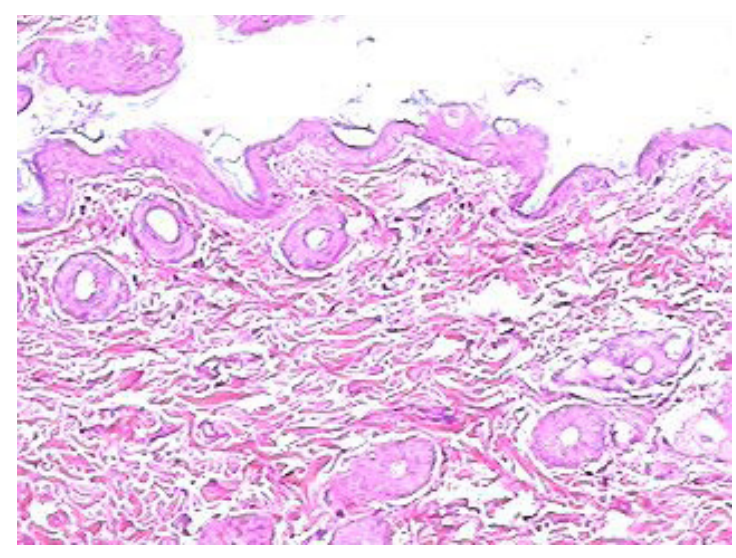

Figure 5. Histological preparation of an animal biopsy of the irradiated group, performed 21 weeks after $S$. schenckii inoculation, and 12 weeks after the first irradiation session (100x magnification). 
observed after the second irradiation, no histological changes were observed. This third biopsy was performed 21 weeks after $S$. schenckii inoculation, and 12 weeks after the first irradiation session, did not show any of the abnormalities indicated in Figures 2 (without irradiation) and 3 (after the first session), in addition to maintaining the normality pattern presented in Figures 1 and 4 (after the second session).

Figure 6 shows a histological section made with biopsy material collected 21 weeks after infection, but of an animal belonging to the control group (without irradiation), and the presence of a quite intense subacute inflammatory (white arrows) and chronic inflammatory (arrows dark) processes, with the presence of granulomas (red arrows). Still for the specimen in question, the results for the Periodic Acid Schiff technique presented positive results, with the presence of countless $S$. schenckii spores.

\section{Discussion}

Advances in antifungal therapy and the indiscriminate use of these drugs in recent years have allowed naturally resistant strains to be selected, making them immune to many conventional treatments. In this sense, the need to develop alternative therapies to antifungals becomes imminent, since several of these microorganisms are associated with difficult-to-cure infections (Donnelly et al., 2008; Hajjeh et al., 1997).

Sporotrichosis, a subcutaneous mycosis that has as its etiological agent the fungus Sporothrix schenckii, and whose incidence is increasing considerably in both humans and domestic animals, is an example of a disease in which the effect of conventional therapies, still of considerable toxicity to the human organism, is quite limited (Chakrabarti et al., 2015; Portuondo et al., 2016).

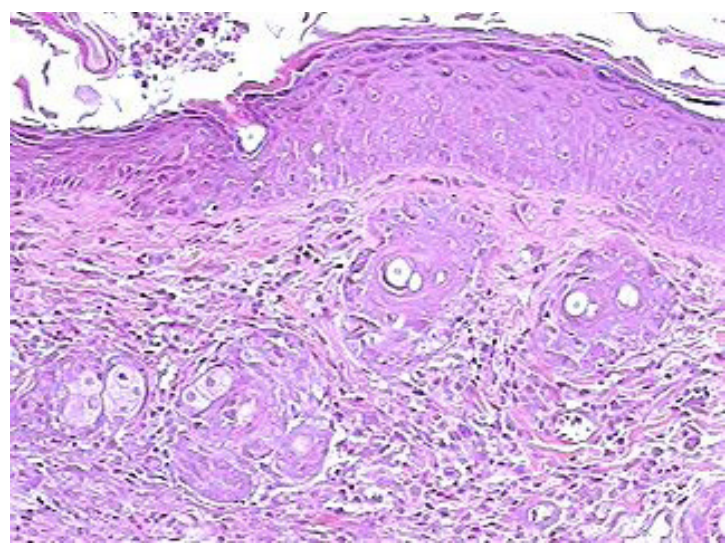

Figure 6. Histological preparation of an animal biopsy of the control group, with the biopsy performed 21 weeks after $S$. schenckii inoculation (100x magnification).
In the present study it was possible to verify that, after the first laser therapy session, the presence of spores, visible in the specimens before the treatment, presented complete remission. The data reported here resemble an in vitro study conducted by Nunes Mario et al., (2014), where $S$. schenckii colonies were submitted to low-power laser sessions. In this work, the authors highlighted the fact that laser photobiomodulation was shown to be considerably effective in the modulation of inflammatory process, immunological activity and biomodulators of tissue reparation, including remission of cutaneous and subcutaneous inflammatory and infections like mycoses, suggesting that phototherapy is a promising alternative for the treatment of sporotrichosis and possibly other subcutaneous mycoses. Still in relation to remission of colonies, in a single case study where a 65 -year-old patient diagnosed with sporotrichosis underwent phototherapy (Alves et al., 2010), the authors described a considerable improvement in the infectious condition, although the patient reported severe pain towards the treatment. In the aforementioned study, in vitro experimentation was also conducted, with satisfactory results regarding the suppression of $S$. schenckii colonies.

Likewise, because of the present research, it was noticed that also after a single laser therapy session, histological abnormalities such as acute inflammatory processes and hyperplasia, as well as the presence of spores, all visible in specimens before treatment, also presented remission; although reticular dermis fibrosis and a mild chronic inflammatory process had persisted. These findings affirm that after a single application of the low-power laser in rodents tissues inoculated with S. schenckii, there is already a considerable reduction of the acute inflammatory process and elimination of the etiologic agent, common in infected tissues.

After the second session of low-power laser photobiomodulation, both the moderate degree of reticular dermis fibrosis and the mild chronic inflammatory process, both persistent after the first session, were no longer present in the biopsied specimen, and remained so before and after the third session. The findings of this investigation allow for the supposition that only two laser therapy sessions were enough for the infected tissues to return to their normal patterns.

Moreover, it is possible to affirm that no histological alteration was due to the application of the low-power laser, since their normal pattern was maintained even after the third laser therapy session. To date, the literature does not describe studies where histological characteristics have been monitored of animal tissues inoculated with the etiological agent of sporotrichosis, and had undergone low-power laser therapy. In this sense, the results of this study confirm for the first time the efficacy of laser therapy in the remission of tissue changes induced by 
sporotrichosis, in addition to showing its efficacy in the eliminating S. schenckii spores; since only tissue samples from biopsies performed in irradiated animals presented aspects considered within the normal standard.

In general, the specimens inoculated with S. schenckii, submitted to laser therapy, presented histological patterns similar to the uninoculated animal, already after the second session. Furthermore, the low-power laser did not cause any damage to the irradiated tissues; since even after the third irradiation session, the specimens were still comparable to the normal animal.

The laser application protocol used in the experiments demonstrated here was based on works already established in the literature (Antunes et al., 2009; Campos, 2013). However, the decision to perform the low-power laser therapy with periods of 30 days between the applications, was in order to observe the cellular behavior during a longer time interval between the sessions; since this is a condition unused and which, to date, has not been used in experiments with $S$. schenckii.

The skin accounts for $95 \%$ of the manifestations of Sporotrichosis. The treatments, although present as a challenge, mainly due to the limitation of treatment options, the high cost and non-adherence on the part of the infected, should be maintained. The abandonment of the treatment was presented as another serious problem. Although all the infected patients are instructed to follow with the complete cycle to the remission of the disease, this does not occur in most cases, and may involve your recurrence.

Some clinical aspects stand out, like the recurrence of injuries, mainly located in the hands after local trauma, and injuries with therapeutic needs more than one year when in immunocompromised or with average time of 12 weeks in healthy patients. Also important to provide information about higher virulence of strains causing infection in patients with lesions of difficult resolution therapy, as well as the patients present a persistent strain, or reinfection by another strain (Campos, 2013; Meinerz et al., 2007; Soukos and Goodson, 2011).

The therapeutic methods, so far, in addition to their associations, established, also present the problem of expensive costs, while extensive treatment and occurrence of various side effects. The therapeutic searches more assertive, lower cost, reduced treatment time and with minimal side effects, or even with the absence of these, turn out to be the best prospects in relation to the treatment of Sporotrichosis.

In the present study, we decided to study the effects of laser phototherapy, instead of photodynamic therapy-PDT, because this method is well diffused this adjuvant therapy and is always dependent of a photosensitizer. In addition studies raise the possibility at PDT in addition against antimicrobial effect in the production of reactive oxygen species, there is a potential effect of low power laser radiation remaining in the target tissue, as well as surrounding us, in cell and tissue photobiomodulation, going on so a photodynamic association with phototherapy.

In this way, the photobiomodulation process, because the low level laser therapy exposes the intact skin the energies that promote the differentiation of cellular and tissue function, as well as inflammatory and activation of the immune system, aiding in the remission of infectious processes and in the repair of injuries through the photobiomodulation effects.

In the process of tissue repair, the photobiomodulation o acts in each of the three phases (inflammatory, proliferative and redesign), providing positive responses in each of them, in addition to the release of biomodulators and biomarkers acting local and systemic tissue, promoting tissue reorganization, in addition to activation of immune response, and modulation of the response in the face of the offending agent-infectious and inflammatory processes and tissue repair. In this step, photobiomodulation is not invasive, it is painless, low-cost and less time compared to others treatments.

This study in animal model conclude that the use of the low-power laser photobiomodulation promoted positive effects on the inactivation of $S$. schenckii in the inoculated animals used in the present experiment, when compared to the control animals (non-irradiated). Histological analysis of the biopsies collected after the laser therapy sessions showed progressive regression of pseudoepitheliomatous hyperplasia and the chronic inflammatory process, common in sporotrichosis, with total remission and return to normality after the second irradiation session, sixty days after inoculation. These results put laser therapy as a very promising alternative in the treatment of S. schenckii infections. Clinical studies are necessary to confirm the efficacy of laser therapy also in human tissues affected by sporotrichosis.

\section{References}

Abreu LM, Batista LV, Pereira GCL, Fonseca LA, Kerppers II, Oliveira CS. Efeito do laser de baixa intensidade no trauma agudo medular: estudo Piloto. ConScientiae Saúde. 2011; 10:11-6. http://dx.doi.org/10.5585/ConScientiaeSaude/2011/ v10n1/2391.

Alves WS, Oliveira GC Jr, Santo LAE, Beserra MRS, Carvalho FAS. Terapia com laser $670 \mathrm{~nm}$ no tratamento da DPOC experimental em ratos. ConScientiae Saúde. 2010; 9:610-7.

Antunes TA, Nobre MO, Faria RO, Meinerz ARM, Martins AA, Cleff MB, Fernandes CG, Meireles MCA. Experimental cutaneous sporotrichosis: in vivo evaluation of itraconazole and terbinafine. Rev Soc Bras Med Trop. 2009; 42(6):70610. http://dx.doi.org/10.1590/S0037-86822009000600018. PMid:20209359. 
Baltazar LM, Ray A, Santos DA, Cisalpino PS, Friedman AJ, Nosanchuk JD. Antimicrobial photodynamic therapy: an effective alternative approach to control fungal infections. Front Microbiol. 2015; 6:202. PMid:25821448.

Barros MBL, Almeida Paes R, Schubach AO. Sporothrix schenckii and Sporotrichosis. Clin Microbiol Rev. 2011; 24(4):633-54. http://dx.doi.org/10.1128/CMR.00007-11. PMid:21976602.

Bjordal JM, Couppé C, Chow RT, Tunér J, Ljunggren EA. A systematic review of low level laser therapy with locationspecific doses for pain from chronic joint disorders. Aust $\mathrm{J}$ Physiother. 2003; 49(2):107-16. http://dx.doi.org/10.1016/ S0004-9514(14)60127-6. PMid:12775206.

Bonifaz A, Rojas-Padilla R, Tirado-Sánchez A, Ponce RM. Sporotrichosis. The state of the art. In Razzaghi-Abyaneh M, Shams-Ghahfarokhi M, Rai M. Medical mycology: current trends and future prospects. New York: CRC Press - Taylor \& Francis Group; 2015. p. 430.

Campos M. Ação da curcumina na terapia fotodinâmica e suas implicações na periodontite: estudo experimental em ratos [tese]. Campinas: Universidade Estadual de Campinas; 2013.

Carlos IZ, Batista-DuharteA. Sporotrichosis: an emergent disease. USA: Springer; 2015. p. 1-23. http://dx.doi.org/10.1007/9783-319-11912-0.

Chakrabarti A, Bonifaz A, Gutierrez-Galhardo MC, Mochizuki T, Li S. Global epidemiology of sporotrichosis. Med Mycol. 2015; 53(1):3-14. http://dx.doi.org/10.1093/mmy/myu062. PMid:25526781.

Dai T, Huang Y-Y, Hamblin MR. Photodynamic therapy for localized infections - state of the art. Photodiagnosis Photodyn Ther. 2009; 6(3-4):170-88. http://dx.doi.org/10.1016/j. pdpdt.2009.10.008. PMid:19932449.

Donnelly RF, McCarron PA, Tunney MM. Antifungal photodynamic therapy. Microbiol Res. 2008; 163(1):1-12. http:// dx.doi.org/10.1016/j.micres.2007.08.001. PMid:18037279.

Feitosa SM, Fernandes KR, Toma RL, De Oliveira P, Rennó ACM, Ribeiro DA. Estudo histológico e biomecânico dos efeitos do Laser terapêutico de baixa potência, $660 \mathrm{~nm}$, em defeito ósseo de tíbias de ratos. ConScientiae Saúde. 2012; 11:60-7.

Giaretta VMA, Santos LP, Barbosa AM, Hyslop S, Corrado AP, Galhardo MS, Nicolau RA, Cogo JC. Low-intensity laser therapy improves tetanic contractions in mouse anterior tibialis muscle injected with Bothrops jararaca snake venom. Res Biomed Eng. 2016; 32(2):153-60. http://dx.doi.org/10.1590/2446-4740.04515.

Giaretta VMA, Santos LP, Barbosa AM, Hyslop S, Corrado AP, Nicolau RA, Cogo JC. Effect of low-level laser therapy (GaAlAs- $\lambda 660 \mathrm{~nm}$ ) on muscle function. Res Biomed Eng. 2015; 31(3):241-8. http://dx.doi.org/10.1590/2446-4740.0736.

Gilaberte Y, Aspiroz C, Alejandre MC, Andres-Ciriano E, Fortuno B, Charlez L, Revillo MJ, Hamblin MR, Rezusta A. Cutaneous sporotrichosis treated with photodynamic therapy: an in vitro and in vivo study. Photomed Laser Surg. 2014; 32(1):54-7. http://dx.doi.org/10.1089/pho.2013.3590. PMid:24328608.

Gould IM. Antibiotic resistance: the perfect storm. Int J Antimicrob Agents. 2009; 34(Suppl 3):S2-5. http://dx.doi. org/10.1016/S0924-8579(09)70549-7. PMid:19596110.
Guirado GMP, Navarro RS, Rossoni RD, Junqueira JC, Feitosa LS. In vitro reduction of pathogenic sporothrix schenckii fungus by photodynamic therapy. Mundo Saúde. 2017;41(2):138-43.

Hajjeh R, McDonnell S, Reef S, Licitra C, Hankins M, Toth B, Padhye A, Kaufman L, Pasarell L, Cooper C, Hutwagner L, Hopkins R, McNeil M. Outbreak of sporotrichosis among tree nursery workers. J Infect Dis. 1997; 176(2):499-504. http:// dx.doi.org/10.1086/514070. PMid:9237718.

Hashmi JT, Huang Y-Y, Osmani BZ, Sharma SK, Naeser MA, Hamblin MR. Role of low-level laser therapy in neurorehabilitation. PM R. 2010; 2(12 Suppl 2):S292-305. http://dx.doi.org/10.1016/j.pmrj.2010.10.013. PMid:21172691.

Hees H, Raulin C, Bäumler W. Laser treatment of onychomycosis: an in vitro pilot study. JDDG J Dtsch Dermatol Ges. 2012; 10(12):913-7. PMid:22897199.

Javed F, Samaranayake LP, Romanos GE. Treatment of oral fungal infections using antimicrobial photodynamic therapy: a systematic review of currently available evidence. Photochem Photobiol Sci. 2014; 13(5):726-34. http://dx.doi.org/10.1039/ C3PP50426C. PMid:24686309.

Kozarev J. Novel laser therapy in treatment of onychomycosis. J Laser Helath Acad. 2010; 1:1-8.

Lopes-Bezerra LM, Schubach A, Costa RO. Sporothrix schenckii and sporotrichosis. An Acad Bras Cienc. 2006; 78(2):293308. http://dx.doi.org/10.1590/S0001-37652006000200009. PMid:16710567.

Mahajan VK. Sporotrichosis: an overview and therapeutic options. Dermatol Res Pract. 2014; 2014:13. http://dx.doi. org/10.1155/2014/272376. PMid:25614735.

Marques GF, Martins ALGP, Sousa JMP, Brandão LSG, Wachholz PA, Masuda PY. Characterization of sporotrichosis cases treated in a dermatologic teaching unit in the state of São Paulo-Brazil, 2003-2013. An Bras Dermatol. 2015; 90(2):273-5. http:// dx.doi.org/10.1590/abd1806-4841.20153447. PMid:25831006.

Meinerz ARM, Nascente PS, Schuch LFD, Cleff MB, Santin R, Brum CS, Nobre MO, Meireles MCA, Mello JRB. In vitro susceptibility of isolates of Sporothrix schenckii to terbinafine and itraconazole. Rev Soc Bras Med Trop. 2007; 40(1):602. http://dx.doi.org/10.1590/S0037-86822007000100012. PMid:17486256.

Nunes Mario DA, Denardi LB, Brayer Pereira DI, Santurio JM, Alves SH. In vitro photodynamic inactivation of Sporothrix schenckii complex species. Med Mycol. 2014; 52(7):770-3. http://dx.doi.org/10.1093/mmy/myu041. PMid:25049038.

Oliveira GC Jr, Santo LAE, Sá HP, Moura Nunes H, Alves WS, Carvalho KC. Efeito da laserterapia de baixa potência na inflamação pulmonar em rattus novergicus. ConScientiae Saúde. 2010; 9:659-66.

Oyarce JA, Garcia C, Alave J, Bustamante B. Epidemiological clinical and laboratory characterization of sporotrichosis in patients of a tertiary care hospital in Lima, Peru, from 1991 to 2014. Rev Chilena Infectol. 2016; 33(3):315-21. http://dx.doi. org/10.4067/S0716-10182016000300012. PMid:27598283.

Portuondo DL, Batista-Duharte A, Ferreira LS, Martínez DT, Polesi MC, Duarte RA, Paula e Silva ACA, Marcos CM, Almeida 
AMF, Carlos IZ. A cell wall protein-based vaccine candidate induce protective immune response against Sporothrix schenckii infection. Immunobiology. 2016; 221(2):300-9. http://dx.doi. org/10.1016/j.imbio.2015.10.005. PMid:26547105.

Rosa ACM, Scroferneker ML, Vettorato R, Gervini RL, Vettorato G, Weber A. Epidemiology of sporotrichosis: a study of 304 cases in Brazil. J Am Acad Dermatol. 2005; 52 (3 Pt 1):451-9. http://dx.doi.org/10.1016/j.jaad.2004.11.046. PMid:15761423.

Silva VS, Abreu EMC, Nicolau RA, Soares CP. Comparative analysis of different doses of coherent light (laser) and non- coherent light (light-emitting diode) on cellular necrosis and apoptosis: a study in vitro. Res Biomed Eng. 2016; 32(4):372-9. http://dx.doi.org/10.1590/2446-4740.00115.

Soukos NS, Goodson JM. Photodynamic therapy in the control of oral biofilms. Periodontol 2000. 2011; 55(1):143-66. http:// dx.doi.org/10.1111/j.1600-0757.2010.00346.x. PMid:21134233.

Takenaka M, Yoshizaki A, Utani A, Nishimoto K. A survey of 165 sporotrichosis cases examined in Nagasaki prefecture from 1951 to 2012. Mycoses. 2014; 57(5):294-8. http://dx.doi. org/10.1111/myc.12158. PMid:24283850. 